\title{
PARA ROMPER CON LA ASIMETRÍA EN LA COMUNICACIÓN DE LA CIENCIA
}

\author{
César Carrillo Trueba*
}

RESUMEN: "Toda noticia científica es una buena noticia", tal pareciera ser la consigna de gran parte de quienes se dedican a la comunicación de la ciencia. Esto se debe a que el marco conceptual de esta actividad sigue siendo la amalgama decimonónica entre desarrollo científico y progreso de la humanidad, por lo que cualquier nuevo "descubrimiento", innovación tecnológica o teoría son vistos como un progreso, por lo tanto intrínsecamente positivos. Es por ello también que cuando hay una noticia que no corresponde a este ideal, se le toma como una anomalía, una desviación de lo que debe ser la actividad científica que es atribuida a causas externas a ella. ¿Cómo romper con esta asimetría?, ¿Cómo dar cuenta de ambos acontecimientos con base en causas similares?, ¿Cómo abordarlos de manera simétrica? En este artículo se analiza la manera como se construyó la relación entre desarrollo científico y tecnológico y progreso social y el papel de la difusión de la ciencia en dicha conjunción. En seguida se esbozan los elementos que pueden intervenir en la construcción de un enfoque simétrico en la comunicación de la ciencia, en concreto por medio de un caso que recientemente levanto revuelo en los medios. La conclusión es que quizá la figura del comunicador de la ciencia resulte un poco limitada para llevar a cabo esta labor de manea simétrica por lo que se propone la creación del oficio de crítico de ciencia.

Palabras clave: Idea de Progreso y Divulgación; Enfoque Asimétrico; Crítico de Ciencia.

\section{BREAKING WITH ASYMMETRY IN SCIENCE COMMUNICATION}

ABSTRACT: "All scientific news is good news," would appear to be the motto of many people devoted to science communication. The reason for this is that the conceptual framework for such activity remains a 19th Century amalgam of scientific and human progress, and therefore any new "discovery," technological innovation, or theory is seen as progress, and therefore intrinsically positive. It is also why, when there is a new item that fails to reflect this ideal, it is taken as an anomaly, a deviation from what scientific endeavor ought to be, which his attributed to external causes. How can we break with this asymmetry? How are we to account for both events based on similar causes? How do we take a symmetrical approach to them? This article analyzes how the relationship between scientific and technological development and social progress and the role of science communication in their convergence was constructed. We then outline the elements that may intervene in the construction of a symmetrical approach to science communication, specifically with reference to a case that recently arouse heated controversy in the media. The conclusion is that the figure of the science communicator may be somewhat constrained in carrying out this task symmetrically, which in turn leads us to propose the creation of the profession of critic of science. Keywords: Idea of Progress and Divulgation; Symmetrical Approach; Critic of Science.
*Biólogo y maestro en antropología; actualmente prepara un doctorado en Antropología Social en la École des Hautes Études en Es editor de la revista Ciencias de la Universidad Nacional Autónoma de México (Departamento de Física, Universidad Nacional Autónoma de México. E-mail:

cesart@ciencias.unam.mx Sciences Sociales de París. 
Desde sus inicios, la ciencia contemporánea se ha caracterizado por revestirse de una aureola que ha hecho de ella una institución intrínsecamente benéfica, positiva, cuyos productos - todos y cada uno de los conocimientos engendrados por ella, los innumerables artefactos tecnológicos - tienen como fin el mejoramiento de la vida de los seres humanos, el progreso de la humanidad. A ella se debe que durante largo tiempo la ciencia ha sido vista - y todavía lo es - como una actividad por encima de todo interés político, ideológico, económico, nacional, es decir, neutra y ajena al contexto social; y quienes se dedican a ella sean consideradas personas incapaces de hacer el mal, que viven por el bien y para el bien de la humanidad y no para su beneficio personal ni el de grupo alguno, lejos de ambiciones y bajas pasiones.

Y es por la misma razón que cuando algo malo resulta de la actividad científica se atribuye a causas distintas de las que provocan bienestar y progreso, generalmente a elementos exteriores a ella, ya sea una mala utilización, una desviación del curso normal del desarrollo científico y tecnológico, un complot, el interés económico de una empresa, el resentimiento o las ambiciones desmedidas de algún científico o la pérdida de control de un proceso que mejor no debería haberse intentado dominar.

Se trata de un claro caso de asimetría, ya que los mismos procesos de generación de conocimiento, vistos desde una perspectiva social, son explicados de manera distinta. El enfoque simétrico, por el contrario, postula que ambos casos deben ser explicados de la misma manera; como lo señala David Bloor para un caso similar, "los mismos tipos de causas deben explicar las creencias 'verdaderas' y las creencias 'falsas"' (BLOOR, 1976: 8.).

Por distintas razones - que van desde la imagen que se ha construido en torno a la figura del científico, plasmada en historietas, películas y novelas, hasta la existencia de grandes laboratorios donde se trabaja en el diseño de armas bacteriológicas, atómicas y químicas, como el napalm usado en Vietnam, lo que alimenta dicho imaginario social - esta dicotomía se ha mantenido durante largo tiempo y prevalece en la actualidad en buena parte de los medios de comunicación. Cada nuevo conocimiento que produce la ciencia - el descubrimiento de una nueva galaxia, de una nueva partícula, la resolución del Teorema de Fermat - es presentado como algo bueno en sí, al igual que toda nueva tecnología y los productos que de ella derivan - por lo que cada vez es más difícil distinguir entre la noticia y el anuncio cuando nos hablan de cómo se concibió, por ejemplo, un nuevo monitor de plasma o una nueva molécula para un medicamento. Es decir, de la ciencia sólo se puede esperar algo bueno, tenga o no aplicaciones prácticas, se entienda o no el aporte para la comprensión del mundo, se sepa o no el impacto que pueda tener en la sociedad, sus posibles repercusiones, etcétera. Toda noticia científica es por tanto una buena noticia.

Es por ello que cuando se presenta algún aspecto negativo de esta actividad es visto por lo general como un caso anormal, y con frecuencia llega a ser manejado en un tono sensacionalista. Así, el fraude cometido por un científico 
coreano es resultado de su ambición, los intentos de un científico italiano por clonar un ser humano son pura locura, el enriquecimiento de uranio en Irán es otro complot islámico, y los efectos dañinos de un medicamento son la consecuencia de la mercantilización de las compañías farmacéuticas que ya no son como antes, cuando se inventó la maravillosa aspirina. El común denominador es la anormalidad de estos acontecimientos, la desviación del sendero del bienpara-la-humanidad que sigue normalmente la ciencia.

La divulgación científica antes, y ahora la comunicación de la ciencia, se han dedicado así, por lo general, a enaltecer el lado positivo de esta actividad en un afán por convencer a la sociedad de las bondades y maravillas de la ciencia, de su importancia para la humanidad, para el progreso de ésta y el mejoramiento del mundo. Poco hablan de las "anomalías" de la ciencia - pues acostumbran mantenerse discretas al respecto para no afectar su intachable imagen -, y cuando lo hacen, suelen recurrir a este tipo de explicaciones.

Su contraparte la constituyen los críticos más radicales de la ciencia, para quienes toda nueva tecnología, toda nueva línea de investigación, anuncia siempre catástrofes múltiples y resultan de complots e intereses ocultos, viendo en todo aquello que produce la ciencia el rostro del mal; y cuando se trata de algo a lo que no pueden adjudicar daño alguno, se mantienen recelosos, con la idea de que no es más que una fachada para engañar.

La pregunta es, ¿cómo salir de esta dicotomía?, ¿Cómo revertir esta asimetría?, ¿Cómo lograr dar cuenta de ambas facetas con base en los mismos procesos, las mismas condiciones iniciales? Un poco de historia puede ayudar, por lo que en un primer tiempo trataremos de delinear la manera como se construyó la relación entre desarrollo científico y tecnológico y progreso social y el papel de la difusión de la ciencia en dicha conjunción. En seguida se esbozarán los elementos que pueden intervenir en la construcción de un enfoque simétrico en la comunicación de la ciencia, tratando de ser más preciso por medio de un caso que recientemente levanto revuelo en los medios. La figura del comunicador de la ciencia puede resultar un poco limitada para llevar a cabo esta labor de manera simétrica por lo que se propone la creación del oficio de crítico de ciencia.

\section{El orden divino y la razón}

A pesar de la imagen que se ha forjado del nacimiento de la ciencia contemporánea, el Renacimiento como escenario, en donde se libra una lucha entre ciencia y religión, una verdadera ruptura con el oscurantismo de la Edad Media, inmortalizada en momentos como la condena de Giordano Bruno a morir en la hoguera o el juicio de Galileo ante el Tribunal del Santo Oficio, prácticamente todos los científicos de esa época - y de las subsecuentes -, eran religiosos, y no pocos incluían en sus trabajos consideraciones propias de todo cre- 
yente - los textos de Newton, Boyle y Descartes, por citar sólo algunos, contienen numerosas alusiones a este tipo de asuntos. De hecho, como lo han señalado algunos historiadores, el primer movimiento que impulsó una serie de cambios en la manera de abordar el conocimiento de la naturaleza proviene del interior de la misma Iglesia y remonta al siglo XII - aunque aparecen algunos rasgos desde antes y continúa en el siglo XIII (LE GOFF, 1957: 61).

En esa época, en varias regiones de Europa, con el desarrollo de las ciudades aparecen los primeros grupos de intelectuales que, pertenecientes al clero o educados en su seno, pero agrupados como un gremio y laborando en las primeras universidades, impugnan el enfoque tradicional de estudiar la naturaleza y proponen que el mundo es regido por una lógica es decir, "si Dios creó la naturaleza, respeta las leyes que le dio. Su omnipotencia no es contraria al determinismo, el milagro se produce en el interior del orden natural" (LE GOFF, 1957: 58). Por lo tanto, los fenómenos naturales no son simples caprichos divinos, obedecen a leyes generales y los humanos pueden acceder a su comprensión.

Las repercusiones de este movimiento no llevaron ciertamente de manera directa al Renacimiento, pero proporcionaron un fuerte impulso a la discusión en torno a una serie de puntos que fueron fundamentales para su génesis e imprimieron en la mentalidad y la vida de los habitantes de las ciudades europeas ideas y actitudes que constituyeron la base social, política y económica de éste, y que formaron parte de la consolidación de lo que es la ciencia contemporánea durante los siglos XVI y XVII, esta vez bajo el impulso de la Reforma, del protestantismo, de la ética puritana que la sostuvo y con ella se desarrolló (THUILLIER, 1988: 79).

Sin embargo, el afán de los protagonistas del Renacimiento, en especial de los científicos, por deslindarse de la manera tradicional de estudiar la naturaleza hizo que se generara una imagen muy negativa de la Edad Media, incluida esta época. Galileo habla de "nuevas ciencias", Kepler de "nueva astronomía", Francis Bacon escribe un Novum Organum - en referencia al Organon escrito por Aristóteles -, alimentando así con nuevos contenidos la polémica entre "modernos" y "antiguos", y reavivándola, ya que todas estas propuestas conformaban poco a poco una nueva filosofía natural que iba en contra de la escolástica, basada en la obra de Aristóteles y, en campos más definidos, en la de autores como Ptolomeo y Galeno, que habían sido reinterpretados a lo largo del tiempo por numerosos teólogos. Y aunque las nuevas ciencias no pretendían excluir la acción divina, no siempre fueron bien recibidas por las autoridades religiosas, ya que, como lo explica Steven Shapin, al criticar los cálculos de Ptolomeo, por ejemplo, se atacaba de facto las Escrituras mismas, debido a la amalgama existente entre la interpretación de la Biblia y los trabajos del astrónomo egipcio. Fue lo que sucedió a Galileo en Italia (SHAPIN, 1996: 173).

No ocurrió lo mismo en otras partes de Europa, en donde se abrieron espacios para el desarrollo de los nuevos enfoques y las intenciones de sus auto- 
res de contribuir a una mejor interpretación de las obras de Dios, de "respaldar y diseminar las creencias religiosas cristianas", ganando así credibilidad y legitimidad. El conflicto no podía ser contra la religión, ya que, como lo sostiene Shapin:

era una época profundamente religiosa y las instituciones religiosas, en todos los países europeos, ejercían un poder secular enorme, tanto por derecho propio como en calidad de asociadas del Estado. Ninguna tendencia cultural nueva que fuera considerada como una amenaza a la religión podía abrigar la esperanza de institucionalizarse (SHAPIN, 1996: 175).

Aun así fue necesario vencer la resistencia del clero tradicional e ir ganando, palmo a palmo, una mayor libertad de pensamiento y acción. En ello la Reforma tuvo un papel preponderante, ya que, al separarse una fracción de la Iglesia - dando origen al Protestantismo - se libró del poder central, y consiguió para una vasta región de Europa las condiciones para el desarrollo de la nueva mentalidad que se esbozaba principalmente en las ciudades. La separación cimbró a tal punto el poder papal y del alto clero, que también tuvo efectos benéficos para los sectores que impulsaban un cambio de mentalidad en las regiones bajo control católico.

En la pugna por una nueva filosofía natural, uno de los primeros puntos a establecer fue la existencia de un orden en la naturaleza, condición indispensable para poder sostener la posibilidad de conocerla y combatir la idea de que el mundo estaba en declive - de lo cual se desprendía que los antiguos fueron mejores que los modernos. Esta cuestión no era trivial, ya que implicaba atentar contra la Divina Providencia y su constante intervención en los asuntos terrenales. John Bury sintetiza estas preocupaciones al parafrasear los argumentos de Louis Le Roy - un francés traductor de Platón y Aristóteles -, expuestos en su obra escrita en 1584:

\footnotetext{
La Naturaleza es ahora la misma de siempre y puede producir inteligencias tan grandes como siempre. Los elementos tienen el mismo poder, las constelaciones siguen manteniendo su orden tradicional, los hombres están hechos del mismo material. No hay nada en esta época que pueda impedir que nazcan hombres de talento semejante al de Platón, Aristóteles o Hipócrates (BURY, J., 1920, p. 52).
}

Así nacieron las leyes de la naturaleza, garantizando la permanencia de las fuerzas que en ella operan y haciendo de Dios un gran legislador, un fino matemático si se consideraba que el Libro de la Naturaleza está escrito en lenguaje matemático o un hábil geómetra al admirarse ante la estructura del sistema planetario. En todas estas metáforas hay un plan preconcebido al efectuarse la creación, el cual los seres humanos pueden conocer. No obstante, de todas ellas perduró la que surgió de la concepción mecanicista que se desarrolló en esos siglos bajo el empuje de la omnipresente máquina, de sus múltiples aplicaciones, principalmente del reloj, el nuevo mecanismo de regulación de la vida social: la 
idea de un Dios relojero, creador de una máquina de gran perfección, a la cual después él mismo dio cuerda (MUMFORD, 1934: 49-50). A esta metáfora subyacía, para algunos autores, la idea de que Dios había creado el universo y las leyes de su movimiento, con lo cual su acción sobre éste es nula actualmente; tal era el caso de Descartes - aunque en algunos textos parece plantearse algunas dudas al respecto. Había también puntos de vista más matizados, como los de Boyle y Newton, quienes pensaban que, aunque limitada, la acción divina es todavía necesaria; el primero planteaba que sin la constante intervención divina no es posible que se mantengan las leyes de la naturaleza, mientras el segundo deducía de sus cálculos que, con el paso del tiempo, el sistema solar tendía a la destrucción, por lo que si esto no había sucedido era gracias a la acción de algún agente natural o del mismo Dios.

La idea de la Divina Providencia parecía tener la piel dura, pero el terreno de disputa se había desplazado al de los cálculos, la experimentación y las teorías científicas. Como lo explica Shapin:

estas diferencias en las estrategias explicativas reflejan concepciones diferentes de lo que era la tarea propia del filósofo natural y del naturalista. Todos los filósofos podían estar de acuerdo, en principio, en que una interpretación reformada de la naturaleza debería apaciguar la duda, proporcionar las creencias correctas y asegurar los fundamentos adecuados del orden moral y, sin embargo, divergir en su noción de cuál era el mejor medio para que la investigación de la naturaleza pudiera cumplir sus tareas (SHAPIN, 1996: 196).

Se puede decir que estaba en juego la manera de obtener y validar el conocimiento, pero esto no sólo implicaba cuestiones de método, sino también aspectos como la utilidad social de éste, la organización de quienes se dedicaban a dicha actividad, su relación con los sectores productivos y el poder, la acción divina, etcétera.

Así, por ejemplo, desde el siglo XII se comienza a insistir en la necesidad de ver directamente las cosas y no referirse a los autores que dicen haberlas visto o las suponen; este punto fue central en el Renacimiento, cuando se propugnaba la observación directa como manera de comprobar lo dicho por los autores clásicos y de generar nuevas evidencias, como ocurría en ese momento con los viajes a otros continentes, de donde se traían especimenes muy diversos - de aquí la fascinación que ejercían los gabinetes de curiosidades, que permitían admirar la gran variedad de formas vivas y de representaciones que existía más allá de las tierras conocidas hasta entonces. Sin embargo, como lo explica Shapin:

la Reforma protestante del siglo XVI acentuó la conveniencia de que cada cristiano se enfrentara directamente con las Escrituras, sin confiar en la interpretación de sacerdotes y papas. Además, la invención de la imprenta, en 1450, facilitó la practicabilidad del imperativo de leer la Biblia personalmente. Un impulso similar dio forma al estímulo para leer personalmente el Libro de la Naturaleza sin confiar en las interpretaciones 
tradicionales de la autoridad institucionalizada. Se consideraba que la experiencia inmediata de la naturaleza era valiosa en la medida en que se entendía que implicaba un compromiso con un texto que tenía autor divino (SHAPIN, 1996: 107).

La experimentación se constituía así en el medio privilegiado para conocer la naturaleza, al punto que se desconfiaba de las teorías generales por recordar la antigua práctica escolástica de sólo teorizar, y la acumulación de datos obtenidos por medios experimentales adquiría un sentido positivo. Como lo describió Thomas Sprat en su historia de la Royal Society, escrita en 1667, cinco años después de ser fundada:

al bajar la filosofía de las alturas a las que se había elevado, al nivel de los ojos y la práctica de los hombres, la Royal Society ha permitido que los conocimientos puedan ahora resistir los embates del Tiempo e incluso los de la Barbarie (NISBET, 1980: 193).

Había además un componente moral, ya que la razón humana era considerada por los puritanos como susceptible de ser influida por la pasión, los deseos, el entusiasmo y otras manifestaciones del espíritu que acercaban al ser humano a los animales, mientras que la experimentación permitía someterla, imponerle rigor, logrando hacerla compatible con la fe.

Asimismo, como lo señala Robert K. Merton, la exaltación del enfoque experimental implicaba una crítica a la contemplación y la ociosidad -“el tiempo debe ser gastado solamente al servicio del deber y no debe desperdiciarse ni una hora en un exceso del dormir o del juego, pues esto es el signo del pecador" - se decía -, por lo que "el experimento era la expresión científica de las inclinaciones prácticas, activas y metódicas del puritano” (MERTON, 1938: 117).

Este sentido práctico llevaba además aparejada la idea de que el conocimiento era un medio para actuar sobre la naturaleza, para acrecentar el poder de la humanidad sobre ésta - "el conocimiento humano y el poder humano son una misma cosa", afirmaba Francis Bacon -, por lo que los resultados prácticos de la ciencia, las posibilidades tecnológicas que de ella derivaban, eran a su vez prueba de su veracidad. Así, por un lado, los científicos buscaban generar un conocimiento práctico, útil para la sociedad, y por el otro, los reyes, príncipes y Estados europeos patrocinaban su trabajo para beneficiarse y cubrirse de gloria, reduciendo cada vez más el apoyo económico que antiguamente brindaba el clero, lo cual, por cierto, no alejaba la ciencia de la religión, como se puede apreciar en otro texto del mismo Bacon, en donde señala que la ciencia se lleva a cabo para "gloria del Creador y el alivio de la situación del hombre" (MERTON, 1938: 117).

No es de extrañar por tanto que científicos de la talla de Hooke, Boyle, Newton y Huyghens dedicaran tanto tiempo a la resolución de problemas prácticos o ligados directamente a éstos. Hooke, por ejemplo, hábil inventor y "encargado de experimentos" en la Royal Society, recibía constantemente peti- 
ciones de numerosos nobles, del Rey y de la misma Society para que colaborara en diversos asuntos; o bien, un problema relevante congregaba a muchos científicos, como sucedió con el drenaje de las minas por medio de bombas, al que se abocaron Torricelli, Pascal, Moray, Huyghens, Papin, Boyle y Hooke, entre otros (MERTON, 1938: 174). La lista de problemas que se convertían en temas de investigación es interminable y el renombre de quienes se dedicaban a su resolución es igualmente asombrosa. Esto no quiere decir que en esa época todo científico se dedicara a resolver cuestiones tecnológicas o problemas ligados a ellas, ni que la economía determinara la actividad científica, pues esta relación es más compleja; pero como señala Merton:

el punto significativo es que mucho de la investigación científica de ese periodo se orientó - no siempre con deliberada intención por parte del científico -, hacia temas que eran profundamente útiles para el desarrollo técnico, temas que, a causa de la importancia económica y social que se les asignaba en este periodo, atrajeron la atención de los científicos como dignos de ulterior estudio (MERTON, 1938: 181).

Así, la relevancia social de los problemas a resolver acrecentaba el reconocimiento social de la actividad científica, lo cual generaba a su vez una mayor demanda del trabajo de los científicos, quienes se veían así motivados en su quehacer cotidiano, fuera éste más estrictamente teórico o práctico; pero sobre todo, este proceso contribuía fuertemente a asentar la idea de que la ciencia es capaz de resolver los problemas de la sociedad, de que la forma de resolverlos es de orden técnico, y fue fundamental en la conformación de la imagen colectiva del científico, la de un grupo de personas dedicadas de manera desinteresada al mejoramiento de la vida de los demás. ${ }^{1}$

En esto último fue determinante la creación, durante la segunda mitad del siglo XVII, en muchas ciudades de Europa, de agrupaciones científicas como la Royal Society de Londres (MERTON, 1938: 246). En ellas se discutían los problemas que enfrentaba cada uno de sus miembros, sus ideas y propuestas, los métodos empleados para abordar su estudio, las técnicas implementadas, las repercusiones económicas, la manera de difundir el conocimiento, el reconocimiento social y el de los compañeros, entre muchas otras cosas, y por medio de éstas se llegaron a establecer aspectos que definieron en gran medida lo que es la actividad científica.

Uno de ellos fue la separación total de los aspectos ideológicos, políticos, religiosos y sociales de los definidos como estrictamente científicos. Sobre este punto ya Francis Bacon había señalado - arremetiendo contra las interminables discusiones, los "monstruosos altercados y cuestiones vociferadas" de los antiguos filósofos -, que:

forzoso es, pues, que el conocimiento de esta calidad sea blanco del desprecio popular, porque el pueblo tiende a desinteresarse por la verdad cuando ve controversias y altercados, y a pensar que si los disputantes no se encuentran nunca es porque están todos extraviados (Shapin, 1996: 165). 
Tal asunto fue de gran importancia en el seno de las nacientes sociedades científicas, ya que pretendían evitar el exceso de debates que aún era común en las universidades, y apegarse en sus sesiones a la discusión de los resultados obtenidos por medio de la experimentación. Con este fin adoptaron de manera consensuada una serie de reglas de conducta que prohibían la discusión de temas de índole política, moral y religiosa, lo que permitía mantener un ambiente propicio para el análisis y la validación de los nuevos conocimientos y los métodos empleados en su obtención. Boyle lo expresa con gran claridad al prevenir contra la introducción de "la moral y la política en las explicaciones de la naturaleza corpórea, donde en realidad todas las cosas se llevan a cabo por medio de leyes mecánicas", ya que esto ha dificultado el "progreso del conocimiento humano" (SHAPIN, 1996: 137). El análisis de Shapin al respecto es concluyente:

\begin{abstract}
las condiciones que se deben cumplir para que se consiga el conocimiento objetivo e inteligible de la naturaleza que es posible lograr son la separación de la filosofía natural de las formas de la cultura en las que se enfrentan las pasiones y los intereses humanos y la interpretación de la naturaleza en sus aspectos mecánicos. Hablar inteligible y filosóficamente de lo que es 'natural' o 'corpóreo' equivale a hablar en términos mecánicos. Esto no implica necesariamente que el mecanismo fuera totalmente adecuado para explicar todos los fenómenos que se presentan a la experiencia humana. Había un importante desacuerdo entre los filósofos modernos a la hora de identificar los fenómenos naturales (SHAPIN, 1996: 137).
\end{abstract}

Esto último, que implicaría un largo análisis, fue también un punto ampliamente discutido y consensuado al interior de las sociedades científicas.

Así, apegándose al ideal impulsado por Bacon de un colectivo organizado y no individuos aislados, las sociedades científicas constituyeron un elemento fundamental a lo largo del proceso que llevó a alcanzar la valorización y el reconocimiento social de la actividad científica, así como a la conformación de la imagen misma que de ella y de los científicos se tiene en la sociedad.

\title{
Progreso científico y progreso social
}

"La vejez del mundo se debe considerar como la verdadera antigüedad; y éste es el atributo de nuestro tiempo, no de la etapa anterior del mundo, cuando vivieron los antiguos" (SHAPIN, 1996: 108). Con esta afirmación asentaba Francis Bacon la preeminencia de los modernos sobre los antiguos - combatiendo así la idea de una degeneración del mundo - y otorgaba un valor al paso del tiempo por la acumulación de saber que éste implicaba - "la propiedad esencial del tiempo consiste en descubrir cada vez más verdad” (BURY, 1920: 61) -, lo cual demostraba por medio de la simple enumeración de tres inventos que tuvieron un enorme impacto social, la imprenta, la pólvora y la brújula, que "han cambiado la apariencia y el estado del mundo entero" (BURY, 1920: 58). 
A esta idea de acumulación de conocimiento y mejoramiento de la vida humana con el paso del tiempo le adjudica el puritanismo reinante entonces una dimensión milenarista, ya que veía en ello el anuncio de una era de oro que prevalecerá antes del regreso de Cristo a la tierra, al mismo tiempo que una condición para que esto suceda. "Los hombres - escribió Calvino - disfrutarán de una gran difusión del conocimiento por toda la tierra gracias a la cual todos los pueblos, incluidos los judíos, se unirían en Cristo" (NISBET, 1980: 185). Pero no sólo eso, al otorgar un valor tan grande al conocimiento y su capacidad de mejorar la vida de los humanos, el puritanismo hace de ello el motor del progreso, el cual no sólo era visto desde el punto de vista natural, sino también religioso. Como señala Nisbet:

\begin{abstract}
los puritanos afirmaban que sólo mediante el cultivo de las investigaciones sobre la naturaleza y el hombre es posible acelerar la llegada del milenio a la tierra. Los puritanos tenían conciencia de los avances que estaban produciéndose a su alrededor en las ciencias, y pensaban que la abundancia de científicos, de centros, institutos y colegios universitarios, y la publicación de los resultados de las investigaciones científicas, hacía que la proximidad del milenio fuera cada vez mayor (NISBET, 1980: 187).
\end{abstract}

Esto resulta claro en la historia de la Royal Society escrita por Sprat, quien afirma que "la empresa cooperativa de muchos científicos hará avanzar más nuestro conocimiento y aumentará el bienestar del hombre" (MERTON, 1938: 256).

Sin embargo, las justificaciones de orden religioso van a ir cediendo el paso a otras seculares, muchas de ellas procedentes de la ciencia misma. Así, la edad de oro por venir comienza a ser vista como algo que puede prolongarse largamente, durante muchos siglos y más, debido a las infinitas posibilidades que contiene el desarrollo científico y tecnológico. De manera que la utopía deja de estar en el espacio, en alguna isla lejana, para ubicarse en el tiempo, en el futuro de la humanidad. O bien, sobre la base del precepto que estipula que "el mismo efecto sigue a la misma causa", se concluye, como lo muestra un texto de la época, que "hay gran probabilidad de que aumente en lo sucesivo el conocimiento del mundo, porque vemos que ya ha ocurrido así" (MERTON, 1938: 257). Igualmente, como lo explica Merton, se aplica a la historia la ley de la aceleración, de manera que "la velocidad (del cambio social) es proporcional al tiempo. Por consiguiente, con el paso del tiempo, es muy probable que la sociedad progrese aún más rápidamente" (MERTON, 1938: 256).

El proceso inverso es también común, esto es, se aplica a la naturaleza la idea del progreso, como sucedió entonces en geología, cuando se desataron fuertes polémicas acerca de la historia de la Tierra. En ese entonces, el reverendo Burnet, cercano amigo de Newton y Halley, se da a la tarea de reconciliar el tiempo cíclico con el tiempo lineal para explicar los grandes cataclismos que había sufrido ésta sin menoscabo de su devenir progresivo. Para este prolífico autor, el conocimiento de dicha historia es finalmente el de Dios y su creación, 
quien imprimió tal desenvolvimiento a la Tierra - "si algún día queremos llegar a conocer los caminos de la Sabiduría Divina, en las obras y la conducta de la naturaleza, debemos no sólo considerar cómo son las cosas, sino cómo llegaron a ser lo que son" (GOULD, 1987: 42). Como lo explica Stephen Jay Gould, la idea de desenvolvimiento, un proceso determinado por designio divino, fue fundamental en la conformación de la idea de evolución.

Así, aun cuando la idea de progreso nace en el seno de una visión religiosa, puritana, en el ethos protestante, y en ella pugnan las artes por ser incluidas, al llegar el siglo XVIII, cuando se instaura una mayor separación entre el poder temporal y el poder espiritual - incluso en los países donde el protestantismo es religión de Estado -, resulta claro que las expectativas de los clérigos no se verán cumplidas. Tampoco lo serán las de los defensores del progreso de las artes, pues se establece poco a poco la idea de que no se puede afirmar que las artes contemporáneas sean mejores que las antiguas, sino tan sólo diferentes; como lo dijera Fontenelle, a diferencia de los estudios científicos, "la vivacidad de la imaginación no requiere una amplia gama de experimentos o una gran cantidad de reglas para alcanzar toda la perfección de que es capaz"(BURY, 1920: 101) - aunque este punto perdurará como controversia durante varios siglos.

El resultado de lo anterior es que el progreso queda fuertemente restringido a la acumulación de conocimiento y las posibilidades que esto representa para el mejoramiento de la vida humana, medido en términos de lo que produce la ciencia para ello - la tecnología, etcétera -, lo cual constituye un razonamiento circular. Como lo señala Merton, dos son los criterios que servirán para determinar el progreso: por un lado los cambios en la organización social, sobre todo en el siglo de las Luces, y por el otro, la aplicación de cánones de utilitarismo, esto es, las normas de uso de los implementos técnicos que orientan una sociedad:

Las pruebas de progreso pueden obtenerse muy fácilmente mediante el uso de tales criterios. Se puede discernir el avance en los instrumentos, científicos y tecnológicos; en los medios de comunicación y de transporte; en los medios de guerra; en resumen, en todos los elementos utilitarios de la vida. Así, una vez concedido un respeto prevaleciente a artefactos que son útiles en este sentido, surge una abrumadora incitación a adherir firmemente a la creencia en el progreso (MERTON, 1938: 259-260).

En suma, se forma la ecuación progreso científico igual a progreso social.

Al mismo tiempo se concreta la imagen de la ciencia como una entidad autónoma situada por encima de la sociedad, purificada por la separación de factores de orden social - políticos, ideológicos y demás -, y provista de una dinámica interna, la de acumular conocimientos - la obligación de los científicos es, como lo afirmara Joseph Glanvill en 1668, "buscar y reunir, observar y examinar, y acumular para las época futuras" (MERTON, 1938: 256). Dicha acumulación es dotada de una estructura como la propuesta por Fontenelle en el siglo 
XVIII: "hay un orden que regula nuestro progreso; cada ciencia se desarrolla después de que se haya desarrollado un determinado número de ciencias precedentes, y solamente entonces; tiene que esperar su vez para romper su cascarón" (BURY, 1920: 105). Y de acuerdo con la idea de un desenvolvimiento, el progreso se torna entonces en proceso ineluctable, en un hecho seguro, necesario; pero también se ve como un proceso infinito, ya desprovisto del milenarismo que le dio origen y de la metáfora de Bacon en donde los modernos son la vejez de la humanidad, ya que ello implicaba la decadencia o una muerte próxima, algo que era cada vez más inconcebible en una sociedad que había conocido tantos cambios en tan poco tiempo y comenzaba a vivir su expansión por el mundo entero. Esto último va a conferir a la idea de progreso un espacio para su desarrollo, ya que los demás continentes aparecen como ubicados en otra temporalidad por tanto donde aún no ha llegado el progreso -, lejos de la vida material que éste ha generado, por lo que es preciso extenderlo a todas estas tierras. La difusión del conocimiento científico es un componente fundamental de tal empresa.

La colonización del mundo por Europa y el auge de la idea de progreso ocurrieron en el siglo XIX, la era de la industria y la ciencia, y es justo cuando aparece la figura del divulgador de la ciencia. Esto no es casual, como lo explica John Bury, ya que:

la popularización de la ciencia [...] era de hecho una condición para el éxito de la idea de Progreso. Esta idea no podía insinuarse en la conciencia pública y convertirse en una fuerza viva de las sociedades civilizadas hasta que la generalidad de los hombres hubiese captado el significado y el valor de la ciencia y hasta tanto los resultados de los descubrimientos científicos no se hubiesen difundido en mayor o menor extensión. Los logros de las ciencias naturales fueron los que más contribuyeron a convertir la imaginación de los hombres a la doctrina general del Progreso (BURY, 1920: 108).

No obstante, el cambio de siglo vino a modificar drásticamente este panorama tan lleno de optimismo.

\section{En pos de la simetría}

El siglo XX fue testigo de la crisis de la idea de progreso y el resquebrajamiento de la fe en la ciencia y su utilidad. La bomba atómica, el deterioro ambiental, la creciente desigualdad entre países y otros acontecimientos más fueron determinantes en esta crisis que tanta tinta ha hecho correr. Sin embargo, la comunicación de la ciencia se ha mantenido en gran medida refractaria a ella y ha seguido presentando la actividad científica como si aún perviviera la fe en la ciencia y el progreso o tal vez con el afán de restaurarla - basta mirar casi cualquier publicación dedicada a ello para darse cuenta - y engendrando de manera inevitable, como ya se vio, su antítesis. 
Afortunadamente hay casos que muestran que es posible romper con la idea de progreso, que logran escapar a esta visión y su antítesis, rompiendo así con dicha asimetría. Uno de los más interesantes es el del recientemente fallecido Stephen Jay Gould, paleontólogo de formación, creador junto con Niles Eldredge de la teoría de la evolución de los equilibrios puntuados, y gran estudioso de la historia de la ciencia. Durante varias décadas, Gould llevó a cabo una labor de divulgación sobre temas cercanos a su área de investigación pero resaltando aspectos generales del quehacer científico, siempre contextualizando el trabajo de investigación a fin de poner en evidencia las múltiples relaciones existentes entre la producción de conocimientos y la filosofía, la ideología, la política, la economía, la historia y demás factores que influyen en ella. Su propuesta fue siempre la de mostrar a un público amplio que la ciencia es una obra humana en toda la extensión de la palabra:

\begin{abstract}
Yo pienso que se debe aprehender la ciencia como un fenómeno social, como una empresa dinámica y no como el trabajo de robots programados para recoger información pura [...] la ciencia, en la medida que es hecha por individuos, es una actividad que hunde sus raíces en la sociedad. Avanza por presentimiento, visión e intuición. Gran parte de su transformación a lo largo del tiempo no debe ser considerada como una aproximación más fina a la verdad absoluta, sino como la modificación de contextos culturales que la influencian fuertemente. Los hechos no son elementos de información puros y sin mancha; la cultura influye también sobre aquello que vemos y en la manera como lo vemos. Además, las teorías no son deducciones inexorables que obtenemos de los hechos. Las teorías más creativas son, con frecuencia, visiones que la imaginación impone a los hechos; las fuentes de la imaginación suelen ser también de origen marcadamente cultural (GOULD, 1983: 16).
\end{abstract}

Su afán crítico se halla presente en toda su obra; pero cada aspecto que coloca bajo la lupa - como el racismo científico, el sexismo, el adaptacionismo en la evolución - jamás es visto como una anomalía, sino como resultado del contexto social en sentido amplio, del estado del saber del momento, de la psicología del científico, etcétera. Un ejemplo de ello es su libro La falsa medida del hombre, dedicado al análisis de las teorías sobre la capacidad intelectual del ser humano que promulgaban la desigualdad entre razas y clases sociales. En él pasa a revista los estudios craneométricos y del volumen del cerebro realizados en el siglo XIX por Samuel G. Morton y Paul Broca, quienes concluían de dichas mediciones la inevitable desigualdad entre negros, indios americanos y demás razas inferiores y los blancos, destinados a dominar el mundo. Gould analiza sus datos, encontrando un sesgo en ellos y en ocasiones un manejo que los empuja en la dirección de lo que ellos pensaban sobre este asunto, pero lejos de reducirlos a una mera anormalidad o una conducta fraudulenta, se da a la tarea de retrazar, paso a paso, el itinerario de estos reconocidos científicos, mostrando que no se trata de algo extrínseco a la ciencia, sino de una característica propia de la producción de conocimientos, en donde los prejuicios de un investigador lo pueden orillar a ese tipo de conductas. 
El caso de las pruebas psicológicas elaboradas posteriormente con el mismo fin, en particular las que determinan el coeficiente intelectual (QI), es más complejo, ya que uno de los precursores de este tipo de pruebas, Cyril Burt, es acusado de fraude científico por varios investigadores y defendido a capa y espada por otros; los primeros lo tachan de racista, mientras los segundos argumentan que él tan sólo puso en evidencia un hecho natural, inobjetable por estar avalado por la ciencia. Gould rompe otra vez con la visión asimétrica al emprender un fino análisis de los métodos estadísticos que empleó este investigador, sus procedimientos analíticos, los artilugios filosóficos, sus prejuicios ideológicos y otros aspectos más, mostrando que Burt era todo menos un científico impoluto, pues era abiertamente racista, pero que tampoco es seguro que hubiese efectuado un fraude deliberado, y de haber sido así, se trata de algo tardío en su trabajo y, en última instancia, de un asunto secundario, ya que lo importante es entender cómo un prejuicio social puede imponerse a los datos que se obtienen y ordenan en una investigación. Su conclusión bien vale la pena:

no hay que efectuar relaciones simplistas entre las preferencias sociales de los hombres de ciencia y las opiniones que profesan en el dominio de la biología. No podemos contentarnos con un esquema maniqueo en el cual los malos defensores de la herencia, relegando ciertas razas, clases y sexos a una inferioridad biológica permanente, se oponen a los buenos defensores del medio, exaltando el valor irreductible de todos los seres humanos (GOULD, 1983: 344).

Este argumento no pretende justificar la actitud de los científicos invocando el contexto social, ni encontrar una posición intermedia, la intención es poder restituir la complejidad de la actividad científica, entender cómo ocurre actualmente la producción de conocimiento, su validación, su difusión, es decir, el funcionamiento de esta gran institución social que es la ciencia. Tal manera de abordar el fraude científico es mucho más real y pedagógica que aquella que sólo acusa o la que lo reduce a una anomalía, como lo hace Lewis Thomas; este autor afirma que cuando se habla de fraude:

se exhuman y se reviven viejos casos para mostrar la existencia de prácticas mentiro-
sas sistemáticas en el proceso científico [...] si así lo desean, se puede considerar que
todos esos casos forman parte de un todo, de una mancha que no ha dejado de cre-
cer a lo largo de la historia de la ciencia. O si prefieren (y personalmente yo así lo pre-
fiero) se pueden ver como anomalías debidas a investigadores de mente desequilibra-
da, o como en el caso de Newton y Mendel, una exageración grosera de la falibilidad
que puede afectar incluso a los más grandes científicos (BROAD y WADE, 1982: 287).

Esta forma de ver el fraude científico es tan difundida que no se conoce con certeza su magnitud, ya que en general, cuando ocurre, es un asunto que se arregla a puertas cerradas, pero los murmullos traspasan paredes y puertas y terminan circulando por los pasillos, por lo que la comunidad termina por enterarse y la impresión es que no es algo tan marginal como se pretende. Es por ello 
que puede ser de gran utilidad el poder explicarlo por medio de los mismos procesos, las mismas condiciones que determinan la generación de conocimientos, es decir, de manera simétrica.

Es este enfoque el empleado por William Broad y Nicholas Wade en su trabajo sobre el fraude en la ciencia, en donde muestran que sus causas residen en la estructura misma del sistema de investigación, en la forma de evaluación, la competencia existente entre laboratorios, la falta de solidez de sus órganos de control interno, de arbitraje, en el arribismo, los medios de financiamiento y otros factores más, propios de la ciencia como institución. "Las raíces del fraude - concluyen -, se hallan en el cesto y no en los frutos podridos de cuya existencia el público se entera de vez en vez" (BROAD y WADE, 1982: 108).

\section{Pasos para un tratamiento simétrico: el caso James Watson}

Un ejemplo bastante reciente que permite esbozar los elementos necesarios para llevar a cabo un tratamiento simétrico en la comunicación de la ciencia - además de claro y sencillo por tratarse de una celebridad científica - es lo que ocurrió en torno a las desafortunadas declaraciones que en 2007 hizo James Watson durante una entrevista publicada en el Sunday Times con motivo de su visita a Londres para presentar su libro Avoid Boreing People. Soy "intrínsecamente pesimista sobre el futuro de África", afirmó el Premio Nobel, pues "todas nuestras políticas sociales están basadas en el hecho de que su inteligencia es igual a la nuestra, cuando todas las pruebas muestran que no es así”. Mi anhelo, dijo, es que todos fuéramos iguales, pero:

la gente que trata con empleados negros ha visto que esto no es verdad [...] No hay una sólida razón para afirmar que las capacidades intelectuales de pueblos separados geográficamente en su evolución resulten haber evolucionado de manera idéntica. Nuestros deseos de adjudicar iguales capacidades para razonar, como si se tratara de una herencia universal de la humanidad, no es suficiente para sostener esto (HUNTGRUBBE, 2007).

Ciertamente, no es la primera vez que Watson hace declaraciones provocadoras a la prensa, generando fuertes reacciones en la sociedad, pero aunque ha asumido algunas de ellas, en general su actitud ha sido la de deslindarse, argumentando que el periodista no entendió bien sus ideas - algo que comúnmente hacen muchos científicos cuando no les parece lo que consignan los medios -, que no era su intención decir las cosas así o alguna otra excusa. Sin embargo, en esta ocasión era imposible tal argucia, ya que, por un lado, la periodista que lo entrevistó ha hecho investigación en biología molecular y durante un año trabajó bajo la dirección del mismo Watson en su laboratorio, y por el otro, debido a que el tema es particularmente sensible en Europa, y sostener argumentos racistas es penado actualmente en varios países. 
Las reacciones fueron por tanto severas, llegando a la cancelación de la presentación de su libro en el Museo Británico, y el repudio de amplios sectores en varios países europeos y en el mundo entero. En un texto ampliamente difundido por los medios ("Cuestionar la inteligencia genética no es racismo"), Watson trató de argumentar que él no es racista pero no hizo más que reafirmar sus ideas con otras palabras:

\begin{abstract}
No entendemos adecuadamente todavía la manera como los diferentes ambientes en el mundo han seleccionado a lo largo del tiempo los genes que determinan nuestra capacidad para hacer cosas diferentes. El irrefrenable deseo de la sociedad hoy día es suponer que capacidades de razonamiento equitativas son una herencia universal de la humanidad. Tal vez sea así, pero querer que sea así simplemente no basta, eso no es ciencia (WATSON, 2007).
\end{abstract}

El escándalo alcanzó proporciones inauditas, al punto que fue retirado del puesto directivo que ocupaba en el Laboratorio de Cold Spring Harbor de Nueva York, que dirigió durante más de cuarenta años y cuya magnitud y recursos deben mucho a su presencia allí. Ciertamente, los detalles de este episodio son muy jugosos y se prestarían para múltiples análisis, pero aquí sólo me interesa la asimetría con que fue tratado el caso. Así, en varios medios se podía leer notas como la siguiente: "En una década uno recibe un Premio Nobel por un descubrimiento asombroso, y un par de décadas después se es un viejo gruñón y tembloroso a quien la familia tal vez tiene miedo hasta de dejarlo jugar con el control remoto de la tele" (The Independent, 19 de octubre de 2007). Es decir, nuevamente encontramos, por un lado, la figura del genio - pues hizo su descubrimiento muy joven -, el laureado Premio Nobel reconocido por sus aportes al conocimiento humano, impulsor de proyectos de gran envergadura como el desciframiento del genoma humano, en fin, la figura paradigmática del científico que logra aportes-sustanciales-para-el-progreso-de-la-humanidad; y por el otro, la de un viejo senil, racista, desacreditado como científico y retirado de sus funciones de manera vergonzosa.

¿Cómo dar cuenta de ambas facetas de manera simétrica? Es aquí donde entran en juego los estudios sobre ciencia, tecnología y sociedad. Veamos. James Watson es una figura central de la biología molecular, uno de sus artífices más connotados. Es por demás sabido que el determinismo biológico prevaleciente en la sociedad burguesa recibió un fuerte impulso con el desarrollo de esta disciplina basada principalmente en una visión reduccionista que hace de los genes los elementos determinantes de la naturaleza humana. ${ }^{2}$ El proyecto de secuenciación del genoma humano se inscribe claramente en esta perspectiva determinista, que puede abarcar con gran facilidad la esfera del intelecto y el comportamiento humano, como ya lo han señalado numerosos autores (LEWONTIN, ROSE Y KAMIN, 1984: capítulos 2 y 3).

Desde esta perspectiva, las diferencias entre humanos, incluidas las capacidades intelectuales, pueden ser explicadas simplemente por la genética. Un 
ejemplo de ello es el libro The Bell Curve: Intelligence and Class Structure in American Life, un bestseller publicado en 1994, en donde se establece una relación entre el éxito económico y el coeficiente intelectual (IQ), el cual, se aduce, estaría más bien ligado a los genes que al nivel socioeconómico, por lo que al abordar la cuestión de la raza, muestra que los afroamericanos son escasos en la elite intelectual de Estados Unidos, de lo cual se deduce que hay una relación entre raza, genes y capacidad intelectual.

El determinismo biológico tiene una larga historia en la sociedad estadounidense - es común explicar las diferencias sociales con base en él -, con episodios dramáticos como las políticas de inmigración establecidas de acuerdo con tales criterios desde fines del siglo XX hasta la década de 1920, y la esterilización forzada de personas consideradas débiles mentales y criminales, que comenzó en el estado de Indiana en 1907 y se extendió a cerca de treinta estados más, alcanzando en 1935 la cifra de 21539 personas esterilizadas - hombres, mujeres y niños (GOULD, 1983: capítulo 6). O bien, el caso del cromosoma criminal, ocasionado por la publicación de varios artículos en la revista Nature acerca de una supuesta relación entre una alteración cromosómica - la existencia de un cromosoma XYY en lugar de XY que se presenta en hombres solamente, cuyos portadores no sufren trastorno o complicación alguna -, y una conducta agresiva y criminal, la cual se basaba en una alta frecuencia de portadores de este cromosoma en instituciones penales y en hospitales psiquiátricos - enfermos mentales con comportamiento agresivo (THUILLIER, 1988b: 158). Una simple relación estadística que alcanzó tal popularidad en los medios que hasta un bestseller se escribió sobre el tema: The XYY Man.

En 1973 una antigua presidenta de la American Association for the Advancement of Science, Bentley Glass, envió a la revista Science un texto en donde mencionaba la posibilidad de detectar el cromosoma fatídico por medio de la amniocitosis, lo cual permitiría efectuar un aborto para librar a la humanidad de todas las lacras que, según ella, generaba este cromosoma. Dos años después, el caso de una mujer que decide abortar al enterarse de que su hijo es portador del cromosoma XYY causa estrépito y pone al descubierto el hecho de que un dato controvertido en el ámbito científico - pues la polémica alrededor de éste nunca cesó - al alcanzar tal difusión, provocó reacciones similares en varias partes de Estados Unidos - aunque no se sabe con certeza cuántas mujeres abortaron por esta razón.

Estos acontecimientos son muestra de que los genes se han instalado en el imaginario social como agentes determinantes de las características de los individuos, de los grupos humanos - sean las llamadas razas, de género, edad, etcétera -, desplazando así algunos de los antiguos determinismos, como el geográfico, y conviviendo con otros que siguen siendo alimentados, como el religioso y el cultural. Los medios han sido un factor fundamental en este avance, baste con ver la portada de algunas revistas de gran circulación como Life, en cuyo número de abril de 1998, por ejemplo, se leía: “`Nació usted así? Personalidad, 
temperamento y hasta decisiones en la vida. Los nuevos estudios muestran que casi todo está en sus genes". Como lo explica Evelyn Fox Keller, "nunca en la historia del gen ha tenido el término tanta fuerza en la imaginación popular como en los últimos años, y en consecuencia, nunca ha tenido el gen más poder de persuasión - es decir, retórico" (FOX KELLER, 2002: 143).

Muchos son los científicos que se han adherido al determinismo biológico y lo han aplicado a los seres humanos sin cuestionarse en lo absoluto, como una simple consecuencia teórica - tal y como lo hace Watson. Las afirmaciones de este último se inscriben por tanto en la línea de pensamiento de los principales científicos del siglo XIX - Darwin, T. H. Huxley, Broca y otros más -, así como la de sus seguidores a lo largo del XX - una larga lista que incluye figuras como R. A. Fisher, C. Davenport, Julian Huxley, F. Crick y E. O. Wilson.

Esto no significa que todo aquel que se adhiera a una idea determinista de los organismos lo aplique automáticamente al ser humano. Hay también una tradición de científicos - ciertamente no tantos - con mayor sensibilidad social, humana, con otra ideología, que se han negado a aplicar los mismos principios a los humanos. Como ejemplo tenemos a Wallace, quien propuso al mismo tiempo que Darwin la teoría de la selección natural pero sostenía que la capacidad intelectual del ser humano no podía ser resultado de la misma, ya que es igual en todos los humanos, y debido a que los habitantes de otros pueblos, como los malayos, no la usa tanto como los europeos, no se puede seleccionar, por ende, algo que no se emplea (THUILLIER, 1980: 52-53) ${ }^{3}$. Asimismo, científicos que compartieron el mismo campo de investigación que Watson están lejos de pensar como él, como Salvador Luria, quien se manifestó con claridad en contra de tales ideas (LURIA, 1984: 325-329), o François Jacob, cuya visión al respecto es completamente distinta (JACOB, 1997: 187-188).

En conclusión, no es raro que un investigador de la talla de Watson haga declaraciones racistas y que éstas formen parte de sus ideas científicas, de sus teorías; más bien se podría decir que es bastante común, ya que hay una larga tradición en la ciencia que siempre ha explicado las diferencias que existen entre los seres humanos con base en un determinismo biológico. Y no se trata de elementos externos, ya que forman parte del mismo corpus científico. Asimismo, dicha tradición coexiste con otras que han elaborado distintas formas de explicar dichas diferencias - algunas con base en un determinismo ambiental, una amplia gama empleando tanto elementos ambientales como genéticos, etcétera. La ciencia es por tanto siempre plural, nunca homogénea, y es por ello necesario precisar las corrientes que hay en su interior, los modos de pensar, las tradiciones de investigación, los estilos en diferentes escalas - del laboratorio a las instituciones internacionales -, los sesgos nacionales, el imaginario que generan, y una serie de elementos más que constituyen un verdadero caleidoscopio. 


\section{La figura del crítico de ciencia}

Muchos son los temas que se podrían tomar para mostrar cómo la visión asimétrica construye la imagen que se tiene de la ciencia, y cómo se puede revertir para proporcionar una imagen desde una perspectiva simétrica. Para ello, la perspectiva de los estudios sobre ciencia, tecnología y sociedad son fundamentales, pero también son valiosos los trabajos de comunicadores de la ciencia como Stephen Jay Gould, Pierre Thuillier y James Gleick, entre otros. Muchos de ellos han ejercido su labor de tal manera que se asemeja más a lo que Thuillier llama "crítica de ciencia", el equivalente de la crítica de arte o de literatura, en donde se abordaría esta actividad contextualizando el trabajo del científico, distinguiendo estilos de investigación, analizando el simbolismo de sus representaciones, su discurso, evaluando la función social de la ciencia, su relación con los ciudadanos, con quienes se acercan a ella, otorgando la debida importancia a la historia, en fin, muchos de los aspectos que son centrales en la crítica de arte, por ejemplo.

En este sentido, ejercer la crítica no significa desvirtuar la ciencia, como claman los defensores de la visión puritana de la divulgación. Más bien, valdría la pena preguntarse, como lo hace Thuillier, si “ ¿se hace progresar la cultura científica al glorificar unilateralmente los 'hechos' y presentar la objetividad como una norma absoluta?" (THUILLIER, 1988: 26). En mi opinión, por muchas razones esta manera de presentar la ciencia resulta más bien perjudicial. Pero baste con señalar tan sólo un punto: uno de los propósitos fundamentales de la divulgación o de la comunicación de la ciencia es el de inculcar un espíritu crítico que, en principio, caracteriza la investigación; mas al presentar esta actividad como si se hiciera publicidad de un producto, como si se tratara de ganar adeptos para una causa, como si el divulgador fuese un misionero, ésta "se inviste con el manto de la religión, fuera del alcance de toda justificación o crítica razonable", como bien lo dice John Ziman (ZIMAN, 1980: 71).

Así, en una sociedad democrática, en donde la ciencia tiene un fuerte impacto en la vida de la gente, la visión puritana tiende a reducir la capacidad de reacción de la sociedad, de poder discutir al respecto, ya que mientras más se le reviste con el manto de la objetividad y la neutralidad, mientras más se muestra como una actividad separada de valores e intereses, como un proceso ineluctable, mayor es el poder que se le otorga a los expertos para intervenir en los asuntos de la sociedad, para dirigirla. Esto constituye una terrible paradoja, pues mientras más separada se le muestra de la ética y la moral, por ejemplo, mayor será su peso moral y ético.

Mostrar los límites de la ciencia, someterla al escrutinio de la sociedad, a la discusión abierta y crítica, no debe ser visto como algo negativo para ella; por el contrario, es desacralizarla, devolverle la pasión o la ambición con que se hace, su grandeza y sus miserias, en fin, todo aquello que hace de esta actividad una creación humana, igual que el arte o la literatura. Por ello, me parece que, 
retomando la propuesta de Pierre Thuillier, en lugar de divulgador o comunicador de la ciencia se debería de instaurar la figura de crítico de ciencia. ${ }^{4}$ 


\section{NOTAS}

${ }^{1}$ Esto se puede apreciar en la New Atlantis de Bacon. pp. 205-211.

2 Véase por ejemplo, Lewontin, 2000: 149.

3 Hay mucha discusión acerca de esto, para algunos se debe a un prejuicio religioso, para otros era su afición espiritista, pero creo que el dato interesante es que consideraba dotados de la misma capacidad a todos los humanos, a pesar de que compartiera la idea de pueblos superiores e inferiores, propia de la época.

4 Éste es el tema de un trabajo en preparación.

\section{REFERENCIAS BIBLIOGRÁFICAS}

BACON, Francis (1627): Instauratio Magna. Novum Organum. Nueva Atlántida, México, Editorial Porrúa, 1980.

BLOOR, David (1976): Sociologie de la logique. Les limites de l'épistemologie (traducción francesa de Knowledge and Social Imagery), París, Pandore, 1982.

BROAD, William y WADE Nicolas (1982): La souris truquée. Enquête sur la fraude scientifique (traducción francesa de Betrayers of the Thruth), París, Seuil, 1987.

BURY, John (1920): La idea del progreso, Madrid, Alianza, 1971.

FOX KELLER, Evelyn (2002): The Century of the Gene, Cambridge Mass., Harvard University Press.

GOULD, Stephen J. (1983): La falsa medida del hombre, Barcelona, Crítica, 2003.

GOULD, Stephen J. (1987): Time's Arrow, Time's cycle, Cambridge Mass., Harvard University Press. HUNT-GRUBBE, C. (2007): The elementary DNA of Dr Watson, Sunday Times, 14 de octubre. JACOB, François (1997): La souris, la mouche et l'homme, París, Odile Jacob.

LE GOFF, Jacques (1957): Los intelectuales de la Edad Media, Barcelona, Gedisa, 1985.

LEWONTIN, Richard (2000): It ain't necessarily so: The Dream of the Human Genome and other illusions, Nueva York New York Review Books.

LEWONTIN, R., ROSE, S. Y L. J. Kamin (1984): Not in Our Genes. Biology, Ideology and Human Nature, Nueva York, Pantheon Books.

LURIA, Salvador E. (1984): Autobiografía de un hombre de ciencia, México, FCE, 1986.

MERTON, Robert K. (1938): Ciencia, tecnología y sociedad en la Inglaterra del siglo XVII, Madrid, Alianza Universidad, 1984.

MUMFORD, Lewis (1934): Técnica y civilización, Madrid, Alianza Universidad, 1982.

NISBET, Robert (1980): Historia de la idea de progreso, Barcelona, Gedisa, 1981.

SHAPIN, Steven (1996): La revolución científica. Una interpretación alternativa, Barcelona, Paidós, 2000.

THUILLIER, Pierre (1980): Le petit savant illustré, París, Seuil.

THUILLIER, Pierre (1988a): De Arquimedes a Einstein, México, Alianza/cnca, 1990.

THUILLIER, Pierre (1988b): Les passions du savoir. Essais sur les dimensions culturelles de la science, París, Fayard.

WATSON, James (2007): To question genetic intelligence is not racism, The Independent, 19 de octubre.

ZIMAN, John (1980): Enseñanza y aprendizaje sobre la ciencia y la sociedad, México, fce, 1985. 
